\title{
Clinical otorhinolaryngological presentation of COVID-19 patients in Saudi Arabia
}

\author{
A multicenter study
}

Laila M. Telmesani, MD, FRCSEd, Danah H. Althomaly, MD, Lamia A. Buohliqah, MD, Roa T. Halawani, MD, Mona M. Ashoor, MD, Marwan J. Alwazzeh, MD, Suad A. Al Mubarak, MD, Maha A. AlHarbi, MD, Rana F. AlMuslem, MD, Sahal S. Arabi, MD, Waleed E. Saleh, MD, Amal Y. ALYosif, MD, Mohammad R. Al Eid, MD, Lena S. Telmesani, MD, Abdulaziz S. AlEnazi, MD.

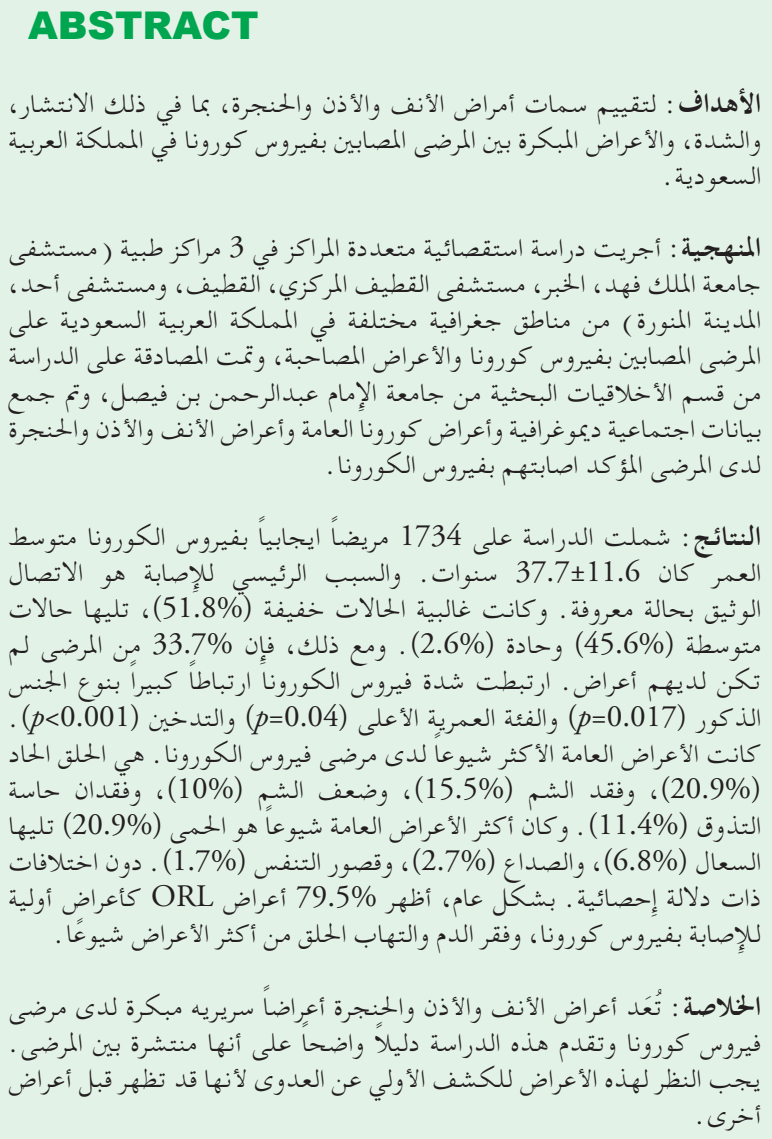

Objectives: To assess the otorhinolaryngological (ORL) symptoms, including their prevalence, severity, and early presentations among coronavirus disease-19 (COVID-19) patients in the Saudi population.

Methods: This was a multicentric, cross-sectional study carried out on severe acute respiratory syndrome coronavirus- 2 positive patients at 3 COVID-19 centres; Imam Abdulrahman Bin Faisal University, King Fahd Hospital of the University, ALKhobar, Qatif Central Hospital, AlQatif, and Ohud Hospital, Al Madinah Al Munawarah, Saudi Arabia. The validated survey consisted of sociodemographic data, general symptoms of COVID-19, and ORL manifestations.
Results: A total of 1734 COVID-19 positive patients were included in the study (mean age: $37.7 \pm 11.6$ years). Most of the cases were mild (51.8\%), followed by moderate $(45.6 \%)$, and severe $(2.6 \%)$ cases. Approximately $33.7 \%$ were asymptomatic. Severity of symptoms was significantly associated with male gender $(p=0.017)$, higher age-group $(p=0.04)$, and smoking $(p<0.001)$. The most common initial ORL presentations were sore throat $(20.9 \%)$, anosmia $(15.5 \%)$, hyposmia (10\%), and loss of taste (11.4\%). Overall, 79.5\% showed ORL symptoms as the initial presenting symptoms for COVID-19, with anosmia and sore throat being the most common symptoms.

Conclusion: This study confirmed the prevalence of ORL symptoms among COVID-19 patients in Saudi Arabia. Moreover, these symptoms could also be considered for early detection of COVID-19 as they might appear prior to other symptoms.

Keywords: COVID-19, coronavirus, otorhinolaryngology, olfactory dysfunction, presentations

Saudi Med J 2022; Vol. 43 (3): 266-274 doi: 10.15537/smj.2022.43.3.20210501

From the Department of Otolaryngology Head and Neck Surgery (L.M. Telmesani, Ashoor, L.S. Telmesani, AlEnazi); from the Department of Internal Medicine (Alwazzeh), College of Medicine, Imam Abdulrahman Bin Faisal University, King Fahd Hospital of the University, from the Department of Otolaryngology - Head and Neck Surgery (Althomaly, AlHarbi), Ministry of Health, Al-Khobar, from the Department of Otorhinolaryngology - Head and Neck Surgery (Buohliqah, Al Mubarak, AlMuslem, ALYosif, Al Eid), Qatif Center Hospital, Ministry of Health, AL Qatif, and from the Department of Otorhinolaryngology - Head and Neck Surgery (Halawani, Arabi, Saleh), Ohud General Hospital, Ministry of Health, AL Medina Al Munawarah, Kingdom of Saudi Arabia.

Received 3rd August 2021. Accepted 26th December 2021.

Address correspondence and reprint request to: Dr. Abdulaziz S. AlEnazi, Department of Otolaryngology - Head and Neck Surgery, Imam Abdul Rahman bin Faisal University, King Fahd Hospital of the University, Al Khobar, Kingdom of Saudi Arabia.E-mail: asenazi@iau.edu.sa ORCID ID: https://orcid.org/0000-0001-7237-4923 
Severe acute respiratory syndrome coronavirus-2 S(SARS-CoV-2), a novel coronavirus, led to a fatal and highly infectious coronavirus disease-19 (COVID-19). ${ }^{1}$ The SARS-CoV-2 first appeared in Wuhan, China in December, 2019 and rapidly transmitted among humans, leading to COVID-19 epidemic in China which was followed by a worldwide pandemic as declared by the World Health Organization (WHO) on March 11, 2020. ${ }^{2}$ According to WHO reports, there have been more than 100 million confirmed cases of COVID-19, with more than 2 million deaths. The first case in Saudi Arabia was confirmed by the Ministry of Health on March 2, 2020. ${ }^{3,4}$

Clinical manifestation of COVID-19 includes wide range of clinical spectrum, ranging from no symptoms to septic shock and multi-organ dysfunctions. This variability in the clinical presentation among COVID-19 patients has also been observed in various studies carried out in Saudi Arabia. ${ }^{5}$ Most of the COVID-19 studies have focused on the lower respiratory tract manifestations and sequels owing to their life-threatening nature. ${ }^{6}$ In symptomatic patients, the most prevalent general symptoms reported were fever, cough, fatigue, myalgia, dyspnea, and loss of appetite. ${ }^{7}$ A retrospective study with 1519 cases in Saudi Arabia reported cough (89.4\%), fever (85.6\%), and sore throat $(81.6 \%)$ to be the most common symptoms. ${ }^{8}$

Since the virus transmission is mediated through the upper respiratory tract, encounters with otorhinolaryngological (ORL) symptoms are unavoidable.' Moreover, increasing information regarding the clinical manifestations of COVID-19 has led to a better understanding of the wide range of symptoms, including ORL symptoms. ${ }^{8,10}$ Pharyngodynia, nasal congestion, rhinorrhea, olfactory, and gustatory dysfunctions are common ORL symptoms of COVID-19. ${ }^{10}$ In a multicentric cohort study, it was found that all the recruited patients showed anosmia which was followed by a high percentage of patients with headache $(69.1 \%)$, rhinorrhoea/nasal obstruction (40\%), and cough (40\%). Data from this study further emphasized the diagnostic importance of ORL symptoms for COVID-19. ${ }^{11}$ Gane et $\mathrm{al}^{12}$ presented a case report along with a case series where they provided evidence for isolated sudden onset anosmia as an initial presentation of COVID-19 and suggested to consider this presentation as management of the disease. A

Disclosure. Authors have no conflict of interests, and the work was not supported or funded by any drug company. study carried out in the Indian population showed $14.8 \%$ prevalence of anosmia in COVID-19 patients. ${ }^{13}$ To assess if loss of smell and taste could be a clinical presentation, Menni et $\mathrm{al}^{14}$ did a community survey via an application and found that 59\% of the COVID-19 patients showed loss of smell and taste as the symptom. Their study found that loss of smell and taste along with fever, persistent cough, and fatigue were predictive symptoms of COVID-19 positive test. This correlation was observed with good specificity (0.86) and average sensitivity $(0.54) .{ }^{14} \mathrm{~A}$ study by Lechien et $\mathrm{al}^{15}$ demonstrated a significant correlation between olfactory and gustatory dysfunctions and COVID-19 infection as the occurrence was found to be 10 times higher in COVID-19 patients compared to COVID-19 negative cases. Furthermore, the ORL symptoms were mainly presented in the mild to moderate form of the disease, and they might be the initial presenting symptoms of COVID-19. ${ }^{16-18}$

A study by Lechien et $\mathrm{al}^{15}$ reported severe olfactory and gustatory dysfunctions without rhinorrhea or nasal obstruction in many COVID-19 positive patients. However, COVID-19 was not suspected at the baseline since fever, cough, or other systemic complaints were absent in these patients. As the ORL symptoms could appear before other symptoms, the physicians should consider these symptoms for the early detection of the infection. ${ }^{15}$

There is a lot of discrepancy in the prevalence of the ORL symptoms between different communities, such as the European and Asian populations, this encouraged us to evaluate the prevalence of these characteristic symptoms in the Saudi population. ${ }^{15,16,19-21}$ Paucity of diagnostic tests was another major reason to understand this clinical presentation and its correlation with COVID-19, as if any early correlation is found between onset of these symptoms and COVID-19 positive cases, this could be used as an early predictor of COVID-19 cases.

We carried out this cross-sectional study and evaluated the clinical presentation, prevalence, and severity of the ORL symptoms among COVID-19 patients from different geographical areas in Saudi Arabia. Since otolaryngologists are approached first by the patients, this might aid them in identifying the suspected cases with atypical presentations.

Methods. A multicentric cross-sectional study carried out including SARS-CoV-2 positive patients with variable ORL symptoms and severity. Patients' information and their clinical data were collected from 3 COVID-19 centers in different regions of Saudi Arabia: Imam Abdulrahman Bin Faisal University, King Fahd 
Hospital of the University, AL Khobar, Qatif Central Hospital, AlQatif, and Ohud Hospital, Al Madinah Al Munawarah, Saudi Arabia. The study protocol was approved by the Institutional Review Board of Imam Abdulrahman Bin Faisal University, AL Khobar, Saudi Arabia on June 2020. The study was carried out according to the principles of Helsinki Declaration.

Collection of the data was between June 2020 and August 2020. Informed consent was obtained from all the patients before their participation in the study. Clinical data was collected electronically via an online survey, which consisted of 3 parts. Prior to the survey, patients were intimated over the phone.

The first part of the survey included questions addressing sociodemographic data and clinical information (medical record number, age, gender, ethnicity, occupation, time of symptoms appearance, time of laboratory diagnosis, comorbidities, smoking history, medication history, and source of the infection). The second part consisted of questions regarding the general symptoms of COVID-19, and the third part included questions specifically on the ORL presentation. A 5-point scale was used to rate the ORL symptoms (0: no symptoms, 1: almost never, 2: sometimes, 3: almost always, and 4: always). We classified the severity of the disease according to the followed measures of the Saudi Ministry of Health where mild cases are the ones who are symptom free or has mild symptoms that do not necessitate hospital admission, moderate are the ones admitted to the medical wards, while the severecritical ones are the ones who needed intensive care unit admission.

Inclusion criteria for the patients in this study included adult over 18 years of age, tested COVID positive confirmed infection, and patients were required to be clinically available for completing the study. The study exclusion criteria were critically ill patients who were unable to fill the survey, patients less than 18 years of age, patients with previous history of smell and taste alternation, sinonasal disease, head trauma, and psychological or neurological disorders.

Statistical analysis. Statistical Package for the Social Sciences for Windows, version 21 (IBM Corp., Armonk, NY, USA) was used to perform the statistical analyses. All categorical variables including gender, age groups, nationality, smoking status, presence of chronic disease (yes/no), ORL symptoms, general symptoms, and severity of COVID-19 were presented as frequency and percentages. Chi-square test was used to check the association between ORL symptoms and severity of COVID-19 and other variables. A $p$-value of $\leq 0.05$ was considered significant.

Results. A total of 1734 SARS-CoV-2 positive patients successfully completed the survey. Out of the 1734 patients, $51.8 \%$ were home quarantined while $33.3 \%$ were admitted in Qatif Central Hospital, Al Qatif, 8.6\% in Ohud Hospital, Al Madinah Al Munawarah, and $6.3 \%$ in Imam Abdulrahman Bin Faisal University, King Fahd Hospital of the University, Al-Khobar.

Among COVID-19 patients, 926 (53.4\%) were male and $898(51.8 \%)$ were female. Approximately $51.8 \%$ had mild symptoms, $45.6 \%$ moderate, and $2.6 \%$ were severe cases (Figure 1). The percentage of moderate and severe cases was significantly higher in males compared to females $(p=0.017)$. The nationality of most of the patients was Saudi (90.2\%), while there

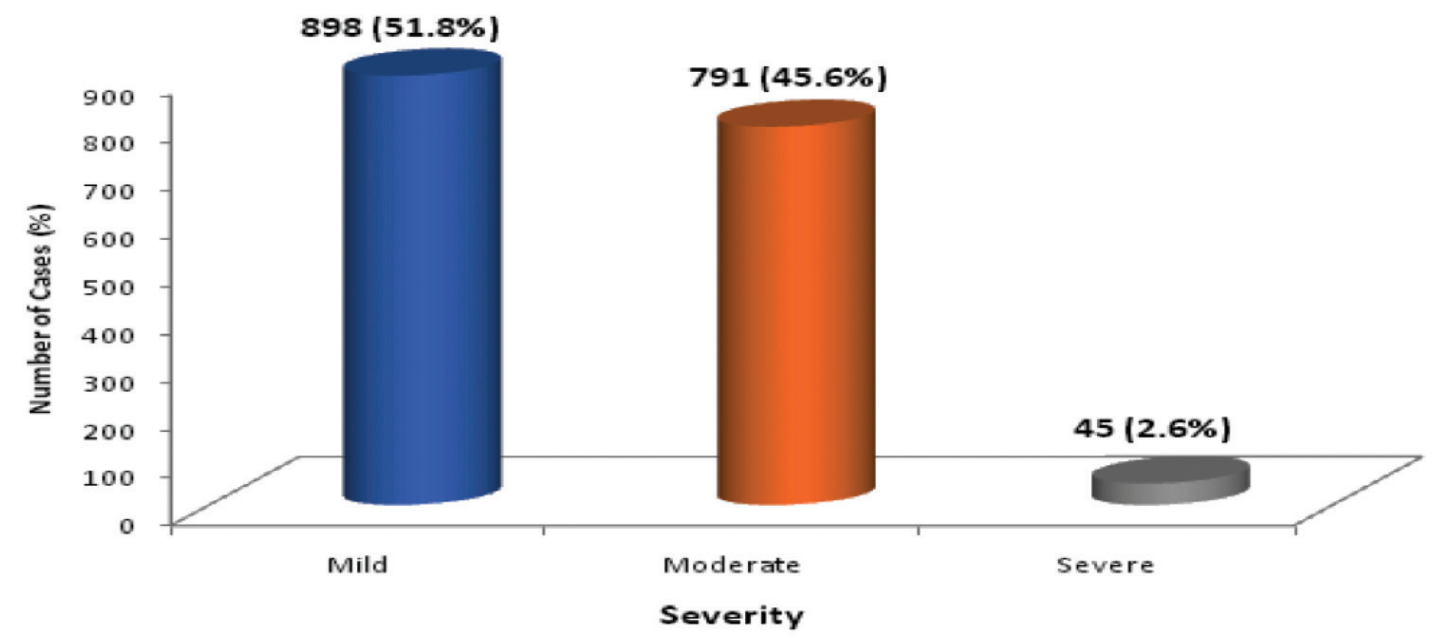

Figure 1 - Severity of coronavirus disease-19 (N=1734). 
were only $9.8 \%$ non-Saudi patients. No statistically significant difference was observed between Saudis and non-Saudis $(p=0.38)$. Most of the patients $(60.9 \%)$ belonged to the age group of 21-40 years, followed by $41-60$ years $(30.5 \%)$. Approximately $4.6 \%$ were $\leq 20$ years of age, and $3.8 \%$ were $>60$ years of age. A statistically significant correlation was observed between the severity of COVID-19 and higher age groups $(p=0.04)$. Among the recruited patients in this study, 291 (16.8\%) were smokers and 1443 (83.2\%) were non-smokers. The association between smoking and severity of COVID-19 was found to be statistically significant $(p<0.001$; Table 1$)$.

No significant association was found between education level and severity of COVID-19 ( $p>0.05)$. Regarding occupation, high proportion of mild COVID-19 cases were students, healthcare workers, and unemployed respondents but the difference was insignificant $(p>0.05)$. On the contrary, significantly high proportion of moderate to severe COVID-19 were non-health worker employees $(p=0.03)$.

The initial ORL and general presenting symptoms of the patients have been listed in Table 2. More than one-fifth presented with sore throat $(20.9 \%)$, followed by anosmia (15.5\%), loss of taste (11.4\%), and hyposmia (10\%). Approximately $4.6 \%$ were initially asymptomatic. Among the general symptoms, majority presented with fever $(20.9 \%)$, followed by cough $(6.8 \%)$, and headache $(2.7 \%)$. On the other hand, the

Table 1 - Demographics of cases with COVID-19 according to severity $(\mathrm{N}=1734)$.

\begin{tabular}{lccccc}
\hline Characteristics & Total & \multicolumn{3}{c}{ Covid-19 severity } & $P$-value \\
& $\mathbf{n}$ & Mild & Moderate & Severe & \\
\hline Gender & & & & & \\
$\quad$ Male & 926 & $452(48.8)$ & $445(48.1)$ & $29(3.1)$ & 0.017 \\
Female & 808 & $446(55.2)$ & $346(42.8)$ & $16(2)$ & \\
Nationality & & & & & \\
$\quad$ Saudi & 1564 & $808(51.3)$ & $722(46.2)$ & $40(2.6)$ & 0.38 \\
$\quad$ Non-Saudi & 170 & $96(56.5)$ & $69(40.6)$ & $5(2.9)$ & \\
Age (years) & & & & & \\
$>18$ & 80 & $41(51.2)$ & $36(45)$ & $3(3.8)$ & 0.04 \\
$21-40$ & 1057 & $555(52.5)$ & $480(45.4)$ & $22(2.1)$ & \\
$41-60$ & 528 & $265(50.2)$ & $249(47.2)$ & $14(2.7)$ & \\
$>60$ & 69 & $37(53.6)$ & $26(37.7)$ & $6(8.7)$ & \\
Smoking & & & & & \\
Smokers & 291 & $76(26.1)$ & $194(66.7)$ & $21(7.2)$ & $<0.001$ \\
$\quad$ Non-smokers & 1443 & $822(57)$ & $597(41.4)$ & $24(1.7)$ & \\
Chronic disease & & & & & \\
$\quad$ Yes & 662 & $327(49.4)$ & $313(47.3)$ & $22(3.3)$ & 0.134 \\
No & 1072 & $571(53.3)$ & $478(44.6)$ & $23(2.1)$ & \\
\hline
\end{tabular}

Values are persented as number and precenteges (\%), n: number, COVID-19: coronavirus disease-19 least common general symptoms were fatigue (2\%), loss of appetite (1.4\%), and myalgia (1.2\%).

Taking into consideration the ORL symptoms and severity of COVID-19 infection, anosmia was the most frequently occurring symptom $(46.2 \%)$, followed by loss of taste (45.2\%), sore throat (37.7\%), and hyposmia (36.3\%). Other symptoms in this category included ear pain pressure $(16.1 \%)$, voice change $(28.4 \%)$, voice fatigue (26.3\%), and breathlessness during speech (23.9\%). Comparison of the ORL symptoms with the severity of COVID-19 showed no significant correlation (Table 3).

When ORL symptoms were compared between 2 age groups ( $\leq 40$ and $>40$ years), it was found that nasal congestion, anosmia, hyposmia, sneezing, loss of taste, daytime sleep, and morning headache were significantly high in patients aged $\leq 40$ years $(p<0.05)$. On the other hand, hearing loss, otorrhea, and loss of voice were significantly high in patients aged $>40$ years $(p<0.05$; Table 4).

Out of the 1734 cases, 70 patients presented with only ORL symptoms as the initial symptoms (Table 5). Among them, 22 (31.4\%) had anosmia, while $16(22.9 \%)$ had hyposmia, one (1.4\%) had loss of taste, $11(15.7 \%)$ had sore throat, $11(15.7 \%)$ had rhinorrhea, $5(7.1 \%)$ had pharyngodynia, and $4(5.7 \%)$ had nasal congestion.

Table 2 - Initial presented symptoms in COVID-19 cases ( $\mathrm{N}=1734)$.

\begin{tabular}{lc}
\hline Symptoms & $\mathbf{n}(\%)$ \\
\hline Otorhinolaryngological symptoms & \\
Anosmia & $269(15.5)$ \\
Hyposmia & $173(10.0)$ \\
Loss of taste & $198(11.4)$ \\
Nasal congestion & $126(7.3)$ \\
Pharyngodynia & $167(9.6)$ \\
Rhinorrhea & $83(4.8)$ \\
Sore throat & $363(20.9)$ \\
None & $80(4.6)$ \\
Anosmia, hyposmia and loss of taste & $275(15.9)$ \\
General symptoms & \\
None & $140(8.1)$ \\
Fever & $362(20.9)$ \\
Cough & $118(6.8)$ \\
Shortness of breath & $29(1.7)$ \\
Headache & $47(2.7)$ \\
Myalgia & $20(1.2)$ \\
Arthralgia & $8(0.5)$ \\
Fatigue & $35(2.0)$ \\
Nausea or vomiting & $18(1.0)$ \\
Abdominal pain & $2(0.1)$ \\
Diarrhea & $8(0.5)$ \\
Loss of appetite & $25(1.4)$ \\
Fever, cough, headache, shortness of breath, & $342(19.7)$ \\
muscle pain, and joint pain & \\
Headache, muscle pain, joint pain, and fatigue & $258(14.9)$ \\
\hline
\end{tabular}


Table 3 - Comparison of ORL symptoms according to severity of COVID-19 (N=1734).

\begin{tabular}{|c|c|c|c|}
\hline \multirow[t]{2}{*}{ Symptoms } & \multicolumn{2}{|c|}{ Severity of COVID-19 } & \multirow[t]{2}{*}{$P$-value ${ }^{*}$} \\
\hline & Mild (n=898) & $\begin{array}{l}\text { Moderate - severe }(\mathrm{n}=836) \\
\mathrm{n}(\%)\end{array}$ & \\
\hline Anosmia & $408(45.4)$ & $393(47.0)$ & 0.504 \\
\hline Loss of taste & $398(44.3)$ & $385(46.1)$ & 0.451 \\
\hline Waking up at night & $348(38.8)$ & $350(41.9)$ & 0.183 \\
\hline Excessive daytime sleep & $337(37.5)$ & $348(41.6)$ & 0.081 \\
\hline Morning headache & $342(38.1)$ & $336(40.2)$ & 0.399 \\
\hline Sore throat & $331(36.9)$ & $322(38.5)$ & 0.49 \\
\hline Hyposmia & $316(35.2)$ & $313(37.4)$ & 0.331 \\
\hline Nasal congestion & $302(33.6)$ & $297(35.5)$ & 0.405 \\
\hline Difficulty falling asleep & $296(33.0)$ & $283(33.9)$ & 0.685 \\
\hline Sneezing & $255(28.4)$ & $240(28.7)$ & 0.89 \\
\hline Voice change & $260(29.0)$ & $233(27.9)$ & 0.612 \\
\hline Rhinorrhea & $253(28.2)$ & $236(28.2)$ & 0.909 \\
\hline Foreign body sensation in throat & $245(27.3)$ & $227(27.2)$ & 0.95 \\
\hline Hoarseness of voice & $231(25.7)$ & $226(27.0)$ & 0.539 \\
\hline Voice fatigue & $235(26.2)$ & $221(26.4)$ & 0.924 \\
\hline Dizziness & $217(24.2)$ & $208(24.9)$ & 0.69 \\
\hline Breathlessness during speaking & $215(23.9)$ & $200(23.9)$ & 0.99 \\
\hline Odynophagia & $204(22.7)$ & $197(23.6)$ & 0.68 \\
\hline Heart burn & $190(21.2)$ & $199(23.8)$ & 0.181 \\
\hline Facial pain/pressure & $166(18.5)$ & $173(20.7)$ & 0.3 \\
\hline Postnasal drip & $172(19.2)$ & $161(19.3)$ & 0.908 \\
\hline Abrupt awakenings accompanied by gasping & $148(16.5)$ & $159(19.0)$ & 0.161 \\
\hline Dysphagia & $145(16.1)$ & $148(17.7)$ & 0.374 \\
\hline Ear pain pressure & $137(15.3)$ & $143(17.1)$ & 0.301 \\
\hline Loud snoring & $112(12.5)$ & $133(15.9)$ & 0.042 \\
\hline Tinnitus & $106(11.8)$ & $126(15.1)$ & 0.041 \\
\hline Ear fullness & $99(11.0)$ & $100(12.0)$ & 0.514 \\
\hline Epistaxis & $42(4.7)$ & $46(5.5)$ & 0.39 \\
\hline Loss of voice & $40(4.5)$ & $45(5.4)$ & 0.387 \\
\hline Hearing loss & $22(2.4)$ & $47(5.6)$ & 0.001 \\
\hline Otorrhea & $22(2.4)$ & $23(2.8)$ & 0.689 \\
\hline
\end{tabular}

ORL: otorhinolaryngology, COVID-19: coronavirus disease-19, ${ }^{*}$ Chi-square test

We also assessed the mode of infection and medication among the recruited patients. It was observed that the main source of infection was close contact with the known COVID-19 infected individuals (46.7\%). Other sources included occupational exposure, travel, and contact with a healthcare worker, while the source of infection was unknown for $653(37.7 \%)$ patients.

The majority of the patients reported taking no medication $(64.9 \%)$.

Discussion. Data regarding clinical presentations of the COVID-19 disease caused by the novel SARS-CoV-2 virus which has caused life threatening pandemic is limited. This study was carried out to record the prevalence and type of ORL symptoms of COVID-19 patients and its relation to the infection severity. We also assessed if the onset of these symptoms could be an early predictor of COVID-19. As for the transmission of this virus, the main mode of SARS-CoV-2 transmission is via airborne droplets which are produced by the cough or sneezing of the infected individuals. ${ }^{10}$ Along with this, virus also transmits by touching hands to mouth, nose, or eye mucosa after contact with the droplets from the infected person. Therefore, there is high probability of clinical presentation in upper respiratory tract, or we can say that the presence of otolaryngologic symptoms is unavoidable. Approximately $25 \%$ of COVID-19 patients might have olfactory dysfunction as the first symptom, which is usually associated with taste dysfunction. ${ }^{10}$ Reports from the European region were 
Table 4 - Comparison of otorhinolaryngology symptoms between different age groups ( $N=1734)$.

\begin{tabular}{|c|c|c|c|}
\hline \multirow[t]{3}{*}{ Symptoms } & \multicolumn{2}{|c|}{ Age (years) } & \multirow[t]{3}{*}{$P$-value ${ }^{*}$} \\
\hline & $\leq 40$ & $>40$ & \\
\hline & \multicolumn{2}{|c|}{ n (\%) } & \\
\hline Anosmia & $602(52.9)$ & $199(33.3)$ & $<0.0001$ \\
\hline Loss of taste & $575(50.6)$ & $208(34.8)$ & $<0.0001$ \\
\hline Waking up at night & $455(40.0)$ & $243(40.7)$ & 0.779 \\
\hline Excessive daytime sleep & $491(43.2)$ & $194(32.5)$ & $<0.0001$ \\
\hline Morning headache & $476(41.9)$ & $202(33.8)$ & 0.001 \\
\hline Sore throat & $436(38.3)$ & $217(36.3)$ & 0.407 \\
\hline Hyposmia & $445(39.1)$ & $184(30.8)$ & 0.0006 \\
\hline Nasal congestion & $416(36.6)$ & $183(30.7)$ & 0.014 \\
\hline Difficulty falling asleep & $375(33.0)$ & $204(34.2)$ & 0.619 \\
\hline Sneezing & $352(31.0)$ & $143(24.0)$ & 0.002 \\
\hline Voice change & $334(29.4)$ & $159(26.6)$ & 0.195 \\
\hline Rhinorrhea & $338(29.7)$ & $151(25.3)$ & 0.053 \\
\hline Foreign body sensation in throat & $316(27.8)$ & $156(26.1)$ & 0.425 \\
\hline Hoarseness of voice & $310(27.3)$ & $147(24.6)$ & 0.201 \\
\hline Voice fatigue & $290(25.5)$ & $166(27.8)$ & 0.279 \\
\hline Dizziness & $287(25.2)$ & $138(23.1)$ & 0.307 \\
\hline Breathlessness during speaking & $262(23.0)$ & $153(25.6)$ & 0.207 \\
\hline Odynophagia & $270(23.7)$ & $131(21.9)$ & 0.401 \\
\hline Heart burn & $241(21.2)$ & $148(24.8)$ & 0.0749 \\
\hline Facial pain/pressure & $225(19.8)$ & $114(19.1)$ & 0.727 \\
\hline Postnasal drip & $217(19.1)$ & $116(19.4)$ & 0.88 \\
\hline Abrupt awakenings accompanied by gasping & $193(17.0)$ & $114(19.1)$ & 0.256 \\
\hline Dysphagia & $189(16.6)$ & $104(17.4)$ & 0.703 \\
\hline Ear pain pressure & $189(16.6)$ & $91(15.2)$ & 0.426 \\
\hline Loud snoring & $125(11.0)$ & $120(20.1)$ & $<0.0001$ \\
\hline Tinnitus & $148(13.0)$ & $84(14.1)$ & 0.503 \\
\hline Ear fullness & $134(11.8)$ & $65(10.9)$ & 0.555 \\
\hline Epistaxis & $58(5.1)$ & $30(5.0)$ & 0.928 \\
\hline Loss of voice & $46(4.0)$ & $39(6.5)$ & 0.021 \\
\hline Hearing loss & $35(3.1)$ & $34(5.7)$ & 0.008 \\
\hline Otorrhea & $23(2.0)$ & $22(3.7)$ & 0.032 \\
\hline
\end{tabular}

in agreement with our study, where the most common ORL symptoms were chemoreceptor disorders, ranging between $19.4-88 \% .^{12,15,19,20}$ In contrast, these symptoms were reportedly uncommon in China. ${ }^{16,21}$

A recent case series with 72,314 COVID-19 patients in Mainland, China, demonstrated pharyngodynia, nasal congestion, rhinorrhea, and anosmia to be the initial presenting symptoms of COVID-19. ${ }^{21}$ Mao et $\mathrm{al}^{22}$ reported loss of smell in 5.1\% and loss of taste in 5.6\% of the patients in their study. This clinical discrepancy might be attributed to lower screening frequency of ORL symptoms in the Chinese population, or viral mutation. ${ }^{15}$

As was seen in our study, olfactory/gustatory dysfunction and nasal obstruction were more prevalent in female patients compared to males, which could be due to the differences in the inflammatory processes between both genders. ${ }^{17,23,24}$

However, Lovato et $\mathrm{al}^{24}$ showed that the patients commonly presented with pharyngodynia (12.4\%), nasal congestion (3.7\%), and rhinorrhea (4\%). Moreover, a multicentric European study of 417 mild-to-moderate COVID-19 patients reported face pain and nasal obstruction as the most common ORL symptoms, in addition to the olfactory and gustatory dysfunctions. ${ }^{15}$

Our study showed high prevalence of ORL symptoms among COVID-19 patients. Data showed that the ORL symptoms seemed to have direct corelation with age and gender, these symptoms were more frequently observed in young patients, whereas fever, fatigue, and anorexia were usually presented by elderly patients. 
Table 5 - Incidence of otorhinolaryngological symptoms as the only presenting symptoms of COVID-19 $(\mathrm{n}=70)$.

\begin{tabular}{cc}
\hline Symptoms & $\mathbf{n}(\%)$ \\
\hline Anosmia & $22(31.4)$ \\
Hyposmia & $16(22.9)$ \\
Loss of taste & $1(1.4)$ \\
Nasal congestion & $4(5.7)$ \\
Pharyngodynia & $5(7.1)$ \\
Rhinorrhea & $11(15.7)$ \\
Sore throat & $11(15.7)$ \\
\hline
\end{tabular}

The European Rhinology Society illustrated that loss of smell can be the presenting symptom before other symptoms such as cough and fever. ${ }^{25}$

Similar observations finding were also reported by Lechien et $\mathrm{al}^{15}$ and Kaye et $\mathrm{al} .{ }^{26}$ The presentation of ORL symptoms, such as anosmia, hyposmia, loss of taste, and sore throat, were one of the most important findings in this study. Furthermore, in an observational study in Australia, sore throat and runny nose were found to be the most common. ${ }^{27}$ Taking olfactory and gustatory dysfunctions into account, a study reported olfactory dysfunction in 68\% of COVID-19 patients which was closely correlated with decreased sense of taste. ${ }^{12}$ Tong et $\mathrm{al}^{28}$ reported that the prevalence of olfactory dysfunctions was $52.7 \%$ and the prevalence of gustatory dysfunctions was $43.93 \%$. While according to the European Rhinology Society, 20-60\% of COVID-19 patients have a loss of smell.

Moreover, Moein et al ${ }^{29}$ established that $98 \%$ of the COVID-19 patients presented with some type of smell disorders, such as hyposmia (13\% mild, 27\% moderate, and $33 \%$ severe) and anosmia (20\%). In a study on 72 patients at the University Hospital of Sassari, hyposmia was observed in $83 \%$ and anosmia in $28 \%$. A decreased sense of taste was observed in $46 \%$, while $1 \%$ reported complete loss of taste. ${ }^{30}$

Lechien et $\mathrm{al}^{15}$ demonstrated that olfactory dysfunction to be a crucial symptom of mild to moderate COVID-19 patients was not associated with other rhinological symptoms. While we found no significant correlation between the ORL symptoms and the severity of COVID-19 infection. Interestingly, isolated anosmia without any other symptoms has also been reported across different countries. ${ }^{18,31}$ Therefore, patients with sudden anosmia should be tested for SARS-CoV-2 presence and considered as potential individuals with COVID-19. ${ }^{18,32}$

When discussing on SARS-CoV-2 infection, it is important to consider the risk factors associated with it. Females have been shown to be significantly more affected by olfactory and gustatory dysfunctions than males, possibly due to the gender-related differences in the inflammatory reaction process. ${ }^{15}$ Some of the risk factors noted to have direct correlation with severity of COVID-19 infections was age, where individuals $\geq 65$ years of age were more vulnerable to higher morbidity and mortality. This was in agreement with our data since we found a statistically significant correlation between the severity of COVID-19 and higher age groups $(p=0.04) .{ }^{16}$ Furthermore, we found significant correlation of disease severity with age, male gender, and smoking which were in coherence with data published by many studies. ${ }^{33,34}$ In this study, the most frequent comorbidities were diabetes, hypertension, and blood disorders. The comorbidities associated with moderate to severe COVID-19 infection included chronic lung diseases, hypertension, and liver disease. A retrospective study carried out in China revealed hypertension, diabetes, cardiovascular diseases, and malignancy to be the most common comorbidities associated with COVID-19, while it was diabetes and hypertension in another study in Saudi Arabia, and high blood pressure, allergic rhinitis, asthma, and hypothyroidism in Europe. ${ }^{6,15,35}$

Chronic systemic diseases such as morbid obesity, diabetes, lung disease, moderate to severe asthma, kidney disease, and liver disease which have been noted to be associated with severe COVID-19 infections. According to a recent study, hypertension, obesity, and diabetes have been listed as the 3 major underlying conditions that result in particularly unfavorable outcomes in COVID-19 patients, which often led to hospitalization. We had similar findings where lung disease, hypertension, and liver disease were significantly associated with moderate to severe COVID-19 $(p<0.05)$. Coronavirus disease-19 can cause multi-organ dysfunction, including kidneys and liver, but mortality is mainly due to the respiratory tract infection by SARS-CoV-2 that leads to severe pneumonia. A previously published report suggested strong correlation between severity of COVID-19 infection and presence of chronic diseases in the infected individuals. ${ }^{36}$ Our study showed that sore throat, anosmia, loss of taste, and hyposmia were the most common initial presenting ORL symptoms in COVID-19 patients. Physicians should consider ORL symptoms specifically olfactory dysfunction for the early detection of COVID-19 infection.

Study limitations. Firstly, our study has been carried out mainly on mild to moderate COVID-19 patients. So, we cannot generalize the result on all infected population including severe cases. From the 
ethical prospective it was difficult to ask severe or lifethreatening cases such as patients in intensivecare units to fill the questionnaire. Secondly, language barrier as the questionnaire was only in Arabic and English editions so some patients who do not speak either language were unable to be included in the study. All of these weaknesses should be considered in future studies.

In conclusion, identification of patients infected with SARS-CoV-2 through specific clinical presentation is not always possible owing to the unspecific nature of the early symptoms. The present study provided clear evidence that ORL symptoms were prevalent among COVID-19 patients in Saudi Arabia and should be considered for early detection.

As anosmia and loss of taste were the most common ORL symptoms, they can be used for the screening of COVID-19 infections. In addition, physicians should give emphasis to all other ORL symptoms for early detection of the COVID-19. Future epidemiological, clinical, and basic science studies should explain the mechanisms underlying the development of these symptoms in such a specific world population.

Acknowledgment. The authors gratefully acknowledge Manuscriptedit (www.manuscriptedit.com) for English language editing.

\section{References}

1. Dogra A, Goyal B, Sharma AM. Corona virus: a novel outbreak. Biomed Pharmacol J 2020; 13: 5-10.

2. Daily briefing: WHO describes coronavirus as a pandemic to spur countries to action. Nature. [Updated 2020; 2020 Jan]. Available from: https://www.nature.com/articles/d41586-02000732-y

3. Barry M, Ghonem L, Alsharidi A, Alanazi A, Alotaibi N, Al-Shahrani F, et al. Coronavirus disease-2019 pandemic in the Kingdom of Saudi Arabia: mitigation measures and hospital preparedness. JNSM 2020; 3: 155-158.

4. Obied DA, Alhamlan FS, Al-Qahtani AA, Al-Ahdal MN. Containment of COVID-19: the unprecedented response of Saudi Arabia. J Infect Dev Ctries 2020; 14: 699-706.

5. Jayaweera M, Perera H, Gunawardana B, Manatunge J. Transmission of COVID-19 virus by droplets and aerosols: a critical review on the unresolved dichotomy. Environ Res 2020; 188: 109819.

6. Alsofayan YM, Althunayyan SM, Khan AA, Hakawi AM, Assiri AM. Clinical characteristics of COVID-19 in Saudi Arabia: a national retrospective study. J Infect Public Health 2020; 13: 920-925.

7. El-Anwar MW, Elzayat S, Fouad YA. ENT manifestation in COVID-19 patients. Auris Nasus Larynx 2020; 47: 559-564.

8. Xu XW, Wu XX, Jiang XG, Xu KJ, Ying LJ, Ma CL, et al. Clinical findings in a group of patients infected with the 2019 novel coronavirus (SARS-CoV-2) outside of Wuhan, China: retrospective case series. BMJ 2020; 368: m606.
9. Özçelik Korkmaz M, Eğilmez OK, Özçelik MA, Güven M. Otolaryngological manifestations of hospitalised patients with confirmed COVID-19 infection. Eur Arch Otorhinolaryngol 2021; 278: 1675-1685.

10. Sedaghat AR, Gengler I, Speth MM. Olfactory dysfunction: a highly prevalent symptom of COVID-19 with public health significance. Otolaryngol Head Neck Surg 2020; 163: 12-15.

11. Salmon Ceron D, Bartier S, Hautefort C, Nguyen Y, Nevoux J, Hamel AL, et al. Self-reported loss of smell without nasal obstruction to identify COVID-19. The multicenter Coranosmia cohort study. J Infect 2020; 81: 614-620.

12. Gane SB, Kelly C, Hopkins C. Isolated sudden onset anosmia in COVID-19 infection. A novel syndrome? Rhinology 2020; 58: 299-301.

13. Mishra P, Gowda V, Dixit S, Kaushik M. Prevalence of new onset anosmia in COVID-19 patients: is the trend different between European and Indian population? Indian J Otolaryngol Head Neck Surg 2020; 72: 1-4.

14. Menni C, Valdes AM, Freidin MB, Sudre CH, Nguyen LH, Drew DA, et al. Real-time tracking of self-reported symptoms to predict potential COVID-19. Nat Med 2020; 26: 1037-1040.

15. Lechien JR, Chiesa-Estomba CM, De Siati DR, Horoi M, Le Bon SD, Rodriguez A, et al. Olfactory and gustatory dysfunctions as a clinical presentation of mild-to-moderate forms of the coronavirus disease (COVID-19): a multicenter European study. Eur Arch Otorhinolaryngol 2020; 277: 2251-2261.

16. Chen N, Zhou M, Dong X, Qu J, Gong F, Han Y, et al. Epidemiological and clinical characteristics of 99 cases of 2019 novel coronavirus pneumonia in Wuhan, China: a descriptive study. Lancet 2020; 395: 507-513.

17. Chary E, Carsuzaa F, Trijolet JP, Capitaine AL, Roncato-Saberan $\mathrm{M}$, Fouet K, et al. Prevalence and recovery rrom olfactory and gustatory dysfunctions in COVID-19 infection: a prospective multicenter study. Am J Rhinol Allergy 2020; 34: 686-693.

18. Krajewska J, Krajewski W, Zub K, Zatoński T. COVID-19 in otolaryngologist practice: a review of current knowledge. Eur Arch Otorbinolaryngol 2020; 277: 1885-1897.

19. Vaira LA, Salzano G, Deiana G, De Riu G. Anosmia and ageusia: common findings in COVID-19 patients. Laryngoscope 2020; 130: 1787.

20. Giacomelli A, Pezzati L, Conti F, Bernacchia D, Siano M, Oreni L, et al. Self-reported olfactory and taste disorders in patients with severe acute respiratory coronavirus 2 infection: a crosssectional study. Clin Infect Dis 2020; 71: 889-890.

21. Guan WJ, Ni ZY, Hu Y, Liang WH, Ou CQ, He JX, et al. Clinical characteristics of coronavirus disease 2019 in China. $N$ Engl J Med 2020; 382: 1708-1720.

22. Mao L, Wang M, Chen S, He Q, Chang J, Hong C, et al. Neurological manifestations of hospitalized patients with COVID-19 in Wuhan, China: a retrospective case series study. SSRN Electron J 2020.

23. Lechien JR, Chiesa-Estomba CM, Place S, Van Laethem Y, Cabaraux P, Mat Q, et al. Clinical and epidemiological characteristics of 1420 European patients with mild-tomoderate coronavirus disease 2019. J Intern Med 2020; 288: 335-344 
24. Hopkins C, Surda P, Kumar N. Presentation of new onset anosmia during the COVID-19 pandemic. Rhinology 2020; 58: 295-298.

25. Lovato A, de Filippis C. Clinical presentation of COVID-19: a systematic review focusing on upper airway symptoms. Ear Nose Throat J 2020; 99: 569-576.

26. Kaye R, Chang CWD, Kazahaya K, Brereton J, Denneny JC 3rd. COVID-19 anosmia reporting tool: initial findings. Otolaryngol Head Neck Surg 2020; 163: 132-134.

27. COVID-19 National Incident Room Surveillance Team. COVID-19, Australia: epidemiology Report 7 (reporting week ending 19:00 AEDT 14 March 2020). Commun Dis Intell (2018) 2020; 44.

28. Tong JY, Wong A, Zhu D, Fastenberg JH, Tham T. The prevalence of olfactory and gustatory dysfunction in COVID-19 patients: a systematic review and meta-analysis. Otolaryngol Head Neck Surg 2020; 163: 3-11.

29. Moein ST, Hashemian SM, Mansourafshar B, Khorram-Tousi A, Tabarsi P, Doty RL. Smell dysfunction: a biomarker for COVID-19. Int Forum Allergy Rhinol 2020; 10: 944-950.

30. Vaira LA, Deiana G, Fois AG, Pirina P, Madeddu G, De Vito A, et al. Objective evaluation of anosmia and ageusia in COVID-19 patients: single-center experience on 72 cases. Head Neck 2020; 42: 1252-1258.
31. Hopkins C, Kumar N. Loss of sense of smell as marker of COVID-19 infection. ENT-UK. [Updated 2020; 2020 Mar 14]. Available from: https://www.google.com/url?sa=t\&rct=j\& $\mathrm{q}=\&$ esrc $=$ s\&source $=$ web \&cd $=$ \&ved $=2$ ahUKEwi5hcHlvJ_2Ah UP8hoKHdXbAtwQFnoECAYQAQ\&url=https\%3A\%2F\%2 Fwww.entuk.org\%2Floss-sense-smell-marker-covid-19-infectio n\&usg=AOvVaw0W88Tj7ToIsMSc1DChCUEy

32. Jayaweera M, Perera H, Gunawardana B, Manatunge J. Transmission of COVID-19 virus by droplets and aerosols: a critical review on the unresolved dichotomy. Environ Res 2020; 188: 109819.

33. Białas AJ, Kumor-Kisielewska A, Górski P. Ageing, sex, obesity, smoking and COVID-19 - truths, myths and speculations. Adv Respir Med 2020; 88: 335-342.

34. Peckham H, de Gruijter NM, Raine C, Radziszewska A, Ciurtin C, Wedderburn LR, et al. Male sex identified by global COVID-19 meta-analysis as a risk factor for death and ITU admission. Nat Commun 2020; 11: 6317.

35. Wang D, Hu B, Hu C, Zhu F, Liu X, Zhang J, et al. Clinical characteristics of 138 hospitalized patients with 2019 novel coronavirus-infected pneumonia in Wuhan, China. JAMA 2020; 323: 1061-1069.

36. Liu H, Chen S, Liu M, Nie H, Lu H. Comorbid chronic diseases are strongly correlated with disease severity among COVID-19 patients: a systematic review and meta-analysis. Aging Dis 2020; 11: 668-678. 